Research Article:

\title{
A New Approach to Monitoring and Evaluation of Cecal Ligation and Puncture Sepsis Model
}

\author{
Arezou Khosrojerdi ${ }^{1}$ (D), Sara Soudi ${ }^{*}$ (D), Ahmad Zavaran Hosseini' ${ }^{1}$, Seyed Mahmoud Hashemi² \\ 1. Department of Immunology, Faculty of Medical Sciences, Tarbiat Modares University, Tehran, Iran. \\ 2. Department of Immunology, School of Medicine, Shahid Beheshti University of Medical Sciences, Tehran, Iran.
}

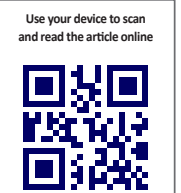

Citation Khosrojerdi A, Soudi S, Zavaran Hosseini A, Hashemi SM. A New Approach to Monitoring and Evaluation of Cecal Ligation and Puncture Sepsis Model. Immunoregulation. 2020; 3(2):97-106. http://dx.doi.org/10.32598/Immunoregulation.3.2.1

doi http://dx.doi.org/10.32598/Immunoregulation.3.2.1

(c) (i) (5)

\section{Article info:}

Received: 13 Mar 2020

Accepted: 05 Jun 2020

Available Online: 01 Jan 2021

\section{Keywords:}

Cecal ligation and puncture, Sepsis, Inflammation, Cytokine, Liver

\begin{abstract}
A B S T R A C T
Background: Sepsis is a systemic inflammatory disease in response to the pathogens that leads to vital organ failures the failure of vital organs. Appropriate animal models should be developed to measure the effectiveness of therapeutic methods. Cecal Ligation and Puncture (CLP) is the most widely used methods of creating the sepsis model. Some variables interfere in the creation of the CLP model which terminated to result in an unrepeatable dynamic of the inflammatory responses. The current research, suggests presents the simultaneous study of inflammatory responses in serum and liver as a criterion for determining the inflammatory status of the CLP model.
\end{abstract}

Materials and Methods: CLP model was induced in 15 female C57bl/6 mice. IL-6, TNF- $\alpha$, IL-10, and TGF- $\beta 1$ cytokines levels were measured at 24,48 , and 72 hours after CLP induction in both serum and liver tissue by ELISA method. Serum levels of liver enzymes were analyzed by the clinical chemistry analyzer. All studies were performed in healthy mice as well. The results were reported as Mean \pm SD.

Results: The levels of IL-10 and TGF- $\beta 1$ in the liver is were significantly $(\mathrm{P} \leq 0.05)$ higher than serum. The production of IL-10 and TGF- $\beta 1$ in the serum and liver reaches its maximum at peaked 24 and 72 hours after CLP induction. The level of TNF- $\alpha$ in the liver is was significantly $(\mathrm{P} \leq 0.05)$ higher than serum with a maximum production 24 hours after CLP induction.

Conclusion: Serum is not a good representative of the inflammatory condition in sepsis. Therefore, it is suggested that local inflammatory responses be considered in evaluating the model, and the determination of drug efficacy.

\footnotetext{
* Corresponding Author:

Sara Soudi, PhD.

Address: Department of Immunology, Faculty of Medical Sciences, Tarbiat Modares University, Tehran, Iran Phone: +98 (21) 82884882

E-mail: soudi@modares.ac.ir
} 


\section{Introduction}

A

nimal models play a key role in studying the host- pathogen interaction and investigating the effectiveness of chemical drugs, immunotherapy methods, and vaccines [1]. If the similarity in of the extrinsic and intrinsic parameters involved in the formation of infection, disease development, and immune response, is greater strong between the animal model and the human, the results of the study in the animal model will be more generalizable to humans [2]. A useful useful good animal model in immunological studies should perfectly mimic the various stages of infectious disease as appeared in humans, including the route of infection, colonization strategy, target tissues, immune evasion, and immune responses [3].

Because of different animal models show variations in pathogenesis and immune responses against to against a definite infectious agent, multiple animal models are used to unravel the complex aspects of immunological responses. The Laboratory mice mouse is the most widely used animal model in infectious diseases [4]. Susceptibility to many human pathogens, easy breeding, and maintenance, a high large numbers of offspring in each generation, having the with the same genetic background, availability easy access for all researchers, ease of easy production of transgenic and humanized mice are among some of the advantages of these this animal models [5].

However, the short lifespan of mice does not allow for complex interventions and long-term evaluations. In additionBesides, the small size of the mice limits restricts access to large volumes of biological fluids such as blood and urine. Although both mice and humans are both mammals and have many similarities in the organs components parts and functions of their immune systems, they respond differently to the same stimuli due to differences in some cases [6]. Persistent hematopoiesis in the spleen, a larger population of lymphocytes to than neutrophils in the peripheral blood, lack of interleukin- 8 and many chemokines, differences in the expression of immunoglobulin receptors and in the pattern of cytokines produced in Th1 and Th2 immune responses in mice, are among some of these cases differences [7] .

Sepsis is an a dysregulated inflammatory disease that results from a malfunction of immune responses to the infectious agents and leads to dysfunction of vital organs, including lungs, kidneys, and liver [8]. The annual prevalence of the disease in developing countries is 3 per thousand 1000 people, and depending on the severity of the disease, $30 \%$ to 50 percent $\%$ of them are at risk of death [9]. Antibiotics are the first line of treatment, but they are not enough to control the disease alone. A range of adjuvant therapies are considered and some adjuvant therapies are required to restore proper organ function in sepsis control, including serum therapy, use of antiinflammatory drugs, and medications that help to restore proper organ function [10].

Because genetic differences, age, sex, and underlying diseases affect the severity of the sepsis and the type of tissue damage, the presence of animal models that can mimic similar human symptoms is essential to assess the effectiveness of drugs [10]. There are Several Several animal models are used for sepsis, each with its own advantages and disadvantages limitations $[11,12]$.

Intraperitoneal injection of Lipopolysaccharide (LPS), is one of the most common methods of endotoxemia and sepsis induction in mice [13]. Since the mortality and severity of inflammation in this model depends on the injection dose of LPS, a range of inflammatory alterations can be simulated similar to those that occur in septic patients [14]. However, LPS is only a single part of the bacteria and does not mimic the immune responses raised in polymicrobial sepsis. Inflammation induced by LPS is more severe than inflammation in human sepsis and subsides in a shorter period of time $[15,16]$.

Intraperitoneal Intraperitoneal or intravenous injection of live bacteria is another way to create a sepsis model. In this procedure, a systemic inflammation similar to sepsis occurs. But injection of a large number injecting a large numbers of bacteria at one time creates a very different condition from the situation than the constant flow of bacteria in septic humans $[14,16]$. Cecal ligation and puncture is one of the most widely used methods of creating the sepsis in an animal model. In this method, one centimeter of the end of the cecum is ligated and one or more holes in the wall of the cecum are created with a needle [17].

In this method Moreover, with permanent polymicrobial leakage into the abdominal space, the two defects problems mentioned in the previous methods have been is are resolved. However, due tobecause of the differences in the length of the ligated cecum and the number of punctures created by different researchers, the results are not reproducible and cannot be generalized [12].

Despite all these these efforts, there is still no animal model that can has still been able to simulate the physiological symptoms, molecular events, immunological responses, and the mortality rate similar to humans yet $[11,12]$. It seems seems means that the application of 
new methods is not enough to improve the quality of the sepsis animal model. Rather, the dynamics of the systemic and organ organ-specific physiological changes, molecular events, and immunological responses must be determined in each method, and the efficacy of drugs should be evaluated in this context. With this approach, Therefore, the findings of the animal model can be generalized to humans and the findings of different models can be compared with each other. In the present study, the dynamics of serum levels of hepatic enzymes, inflammatory and anti-inflammatory cytokines in both serum and liver tissue have been were investigated in a CLP-induced sepsis mouse model.

\section{Materials and Methods}

Healthy female C57BL/6 mice (Six to eight 6-8 weeks old) were purchased from Pasteur Institute, Tehran.

Creation of sepsis model using cecal ligation and puncture

1. Use C57BL/6 mice (6-8 weeks old) are used are used for this method. To anesthetize the mouse, we prepared a solution of 3:1 ketamine $(75 \mathrm{mg} / \mathrm{kg}$ ) and xylazine $(4 \mathrm{mg} /$ $\mathrm{kg}$ ). Dilute the solution with $4 \mathrm{ml} \mathrm{mL}$ of PBS. As a guide, administered inject $100 \mu \mathrm{l} \mu \mathrm{L}$ of the diluted solution into a 20-gram mouse.
2. Shave the mouse abdomen and clean region this area by first by adding betadine solution followed by cleaning and then cleaning it with a 70\% alcohol (Figure 1A).

3. Cut 1 to $2 \mathrm{~cm}$ of skin and peritoneal membrane in the abdomen midline under sterile conditions and expose the cecum (Figure 1 B-C)

4. To cause mild sepsis, ligate the half of the cecum tightly with a 4.0 silk suture and perforate once on the cecum once with an 18-G needle (Figure 1 E-H). Note that the ligated cecum length is related to disease severity. If the distance between the distal end of the cecum and the ligation point is less than $1 \mathrm{~cm}$, moderate sepsis will occur and severe sepsis will occur if it is higher than $1 \mathrm{~cm}$ and if it is more than $1 \mathrm{~cm}$, severe sepsis will occur [18]. Additionally, the number of punctures and the needle gage gauge affect the severity of sepsis.

5. The cecum is then gently squeezed to extrude a small amount of feces from the perforation sites Then gently squeeze the cecum to remove a small amount of feces from the perforated area (Figure 1H).

6. Return the cecum to the abdominal cavity and close the peritoneal membrane and skin with a 4.0 suture (Figure 1I-L).
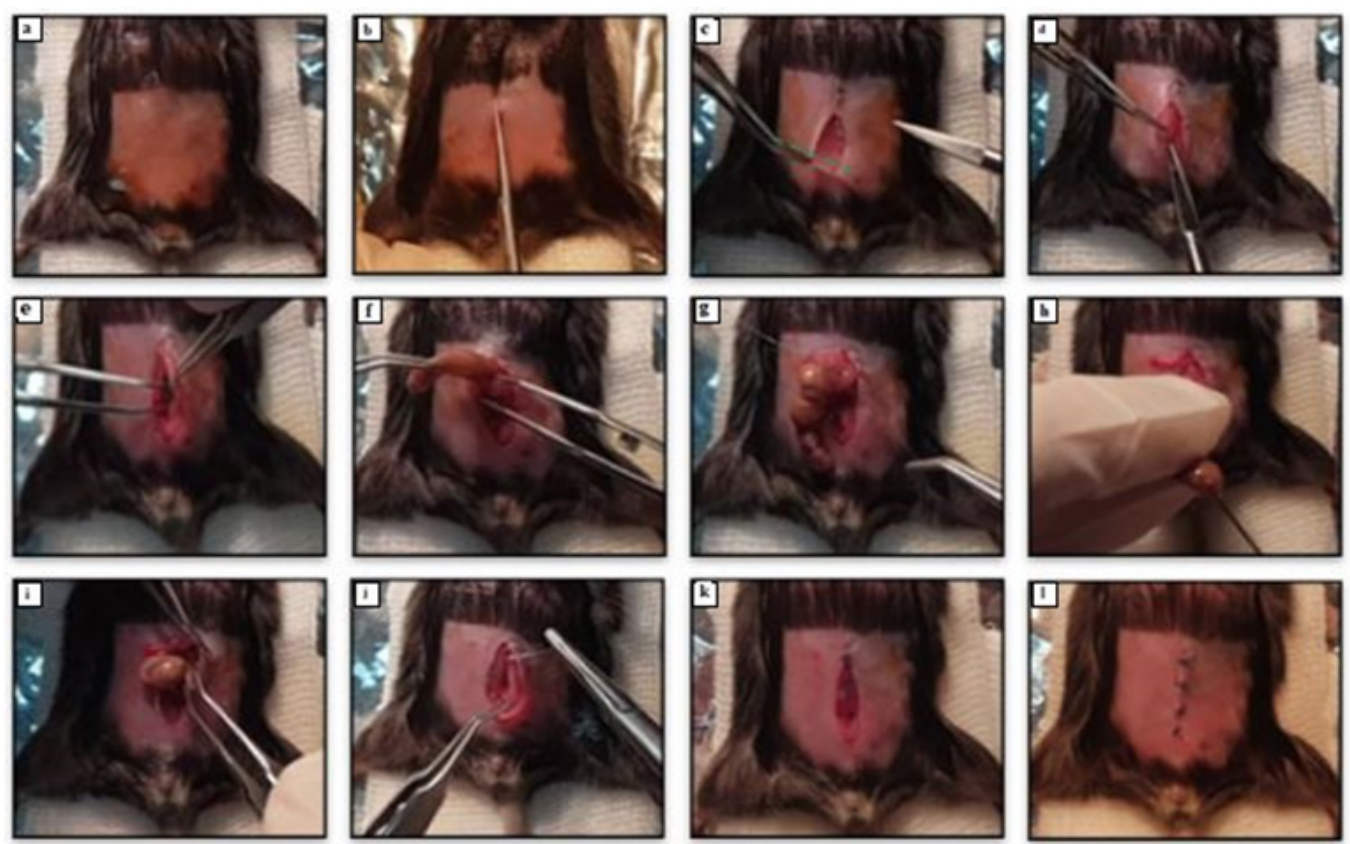

IminunoReculation

Figure 1. Abdominal area of the mice was disinfected after shaving

A: The cecum was revealed with the help of laparotomy; B-F: Ligate Half of the cecum was ligated with a 4-0 suture to cause moderate sepsis; and G: Punctured once with an 18G needle; H:The fecal material was gently squeezed at the end of the cecum to ensure the hole was opened; I-L: The cecum was returned to the cavity of the abdomen abdominal cavity, and the layers were sutured. 
7. Finally, resuscitate the animals by subcutaneously administering injection $1 \mathrm{ml} \mathrm{mL}$ of 0.9 percent $\%$ prewarmed saline solution.

8. Immediately, settle the mice to a cage with exposure of an infrared heating light, until recovery from anesthesia Immediately place the mouse in a cage exposed to infrared light to regain consciousness. Provide enough food and water for them it with enough water and food. The same process is performed repeated for the sham group as a control group without ligation and puncture of the cecum.

\section{Liver enzyme analysis}

For serum preparation, blood obtained by puncture of the heart of all septic and healthy mice To make the serum, blood was obtained by puncturing the hearts of both septic and healthy mice. After clot formation, blood samples were centrifuged to isolated serum at $2000 \mathrm{~g}$ at $4^{\circ} \mathrm{C}$ for 10 minutes to isolated serum. Aspartate and alanine aminotransferase (AST, ALT) levels in serum samples were analyzed by clinical chemistry analyzer to determine in vivo liver dysfunction. This assay was performed at at within 24,48 , and 72 hours post after sepsis induction.

\section{Cytokine analysis}

In order to To determine liver pro/anti-inflammatory secretions, at at within 24, 48, and 72 hours post after sepsis induction, liver tissues of five septic and five healthy mice were collected and homogenized in RIPA (radioimmunoprecipitation assay) buffer containing protease inhibitors. The obtained homogenates were centrifuged at $3000 \mathrm{~g}$ at $4^{\circ} \mathrm{C}$ and stored at $-20^{\circ} \mathrm{C}$. The total protein of each sample was estimated by the Bradford assay. All samples were diluted and used at a concentration of $50 \mu \mathrm{g} / \mathrm{ml} \mathrm{mL}$ for ELISA (Enzyme-linked immunosorbent) test. Serum samples were prepared as de- scribed in the previous section and used in 1: 10 dilutions in ELISA. The amount of IL- 6 , TNF- $\alpha$, TGF- $\beta 1$, and IL10 cytokines was measured in both serum and liver using an R\&D DuoSet ELISA kits including, DY406-05, DY410-05, DY1679-05, and DY417-05, respectively.

\section{Statistical analysis}

All studies were performed on 15 healthy and 15 CLP induced sepsis mice. The serum of each mouse was examined separately, in triplicate. All data are presented are was given as Mean \pm SD. A One-way ANOVA (analysis of variance) method was used to explain significant variations among groups. The $\mathrm{P}$-values of $<$ less than 0.05 were has been was defined statistically as a significant difference, statistically.

\section{Results}

Increased of liver enzymes in the serum of sepsis septic mice

The levels of ALT and AST in the serum of the CLP group have significantly increased significantly compared with with to the sham group $(\mathrm{P}<0.05)$. In addition, this rise has increased over time within in the CLP group. An increase in Elevation of these enzymes suggests indicated dysfunction and destruction of the liver tissue, as which is one of the most important organs involved in sepsis (Figure 2).

\section{Significant rise in inflammatory cytokine levels in} the serum of septic Mice

In the CLP group, the serum levels of inflammatory cytokines TNF- $\alpha$ and IL-6 increased significantly compared with with to the sham group $(\mathrm{P}<0.05)$. The level of IL.10 in the serum also increased significantly compared with the sham group following the body's efforts
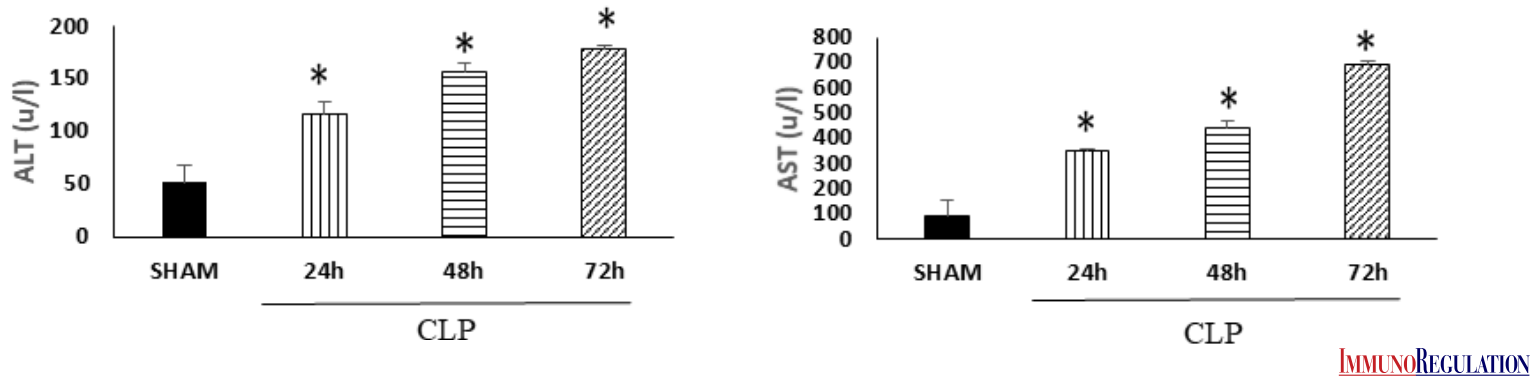

Figure 2. The hepatic enzymes level in the serum of CLP-induced septic mice significantly increased compared to the sham group. $\mathrm{P}<0.05$ defined as significant. 
to control inflammation Because of the body's efforts to control inflammation, serum IL. 10 level also increased significantly compared to the sham group $(\mathrm{P}<0.05)$. IL6 , the most important sepsis inflammatory cytokine, decreases over time, but continues $d$ to be higher than rise in the sham group Whereas while over time TNF- $\alpha$ gradually rises increased. As the amount of inflammatory cytokines increased, the amount of TGF- $\beta$ in the serum shows ed a downward trend (Figure 3 ).

Induction of pro/anti-inflammatory cytokines in the liver of septic mice

The inflammatory and anti-inflammatory cytokine expression in liver tissue is was slightly different from that observed in serum. The expression of TNF- $\alpha$ increased significantly in the liver tissue of the CLP group compared to the sham group liver $(\mathrm{P}<0.05)$. However, TNF- $\alpha$ cytokine production during 72 hours has a downward trend declined within 72 hours. IL- 6 is was another inflammatory cytokine that is was induced significantly in the liver of septic mice as compared to the sham group $(\mathrm{P}<0.05)$, and shows ed an increasing trend within 72 hours. Concomitant to the increase in With increasing IL-6 cytokine level, the production of anti-inflammatory cytokines such as IL-10 and TGF- $\beta 1$ increased significantly $(\mathrm{P}<0.05)$ in the liver of septic mice (Figure 4$)$.
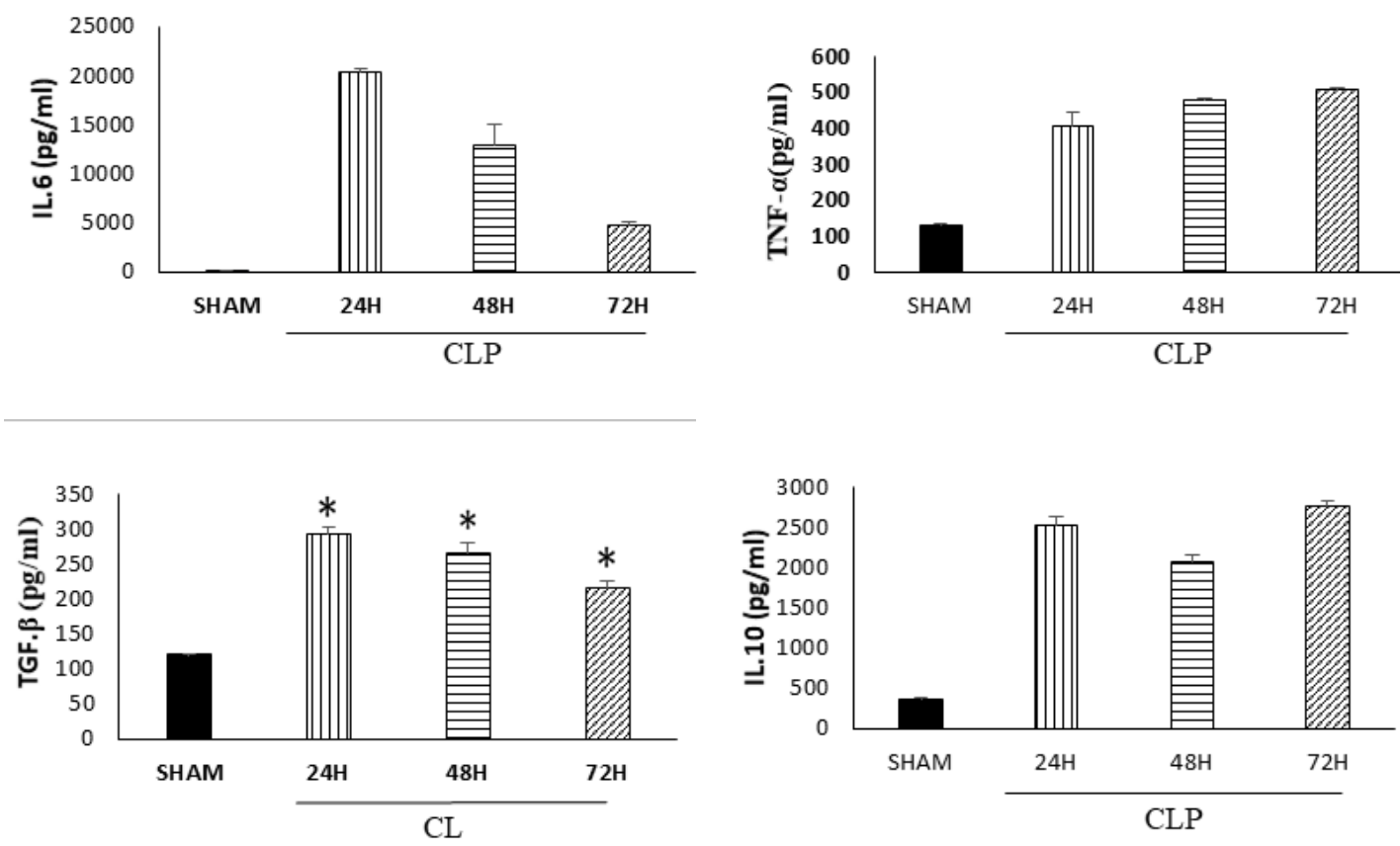

IMMUNoREgulation

Figure 3. Dynamic of cytokine production in the serum of CLP- induced sepsis mice

Both inflammatory and anti-inflammatory cytokines levels in the serum of septic mice shows a significant increase compared to the sham group. $\mathrm{P}<0.05$ defined as significant. 

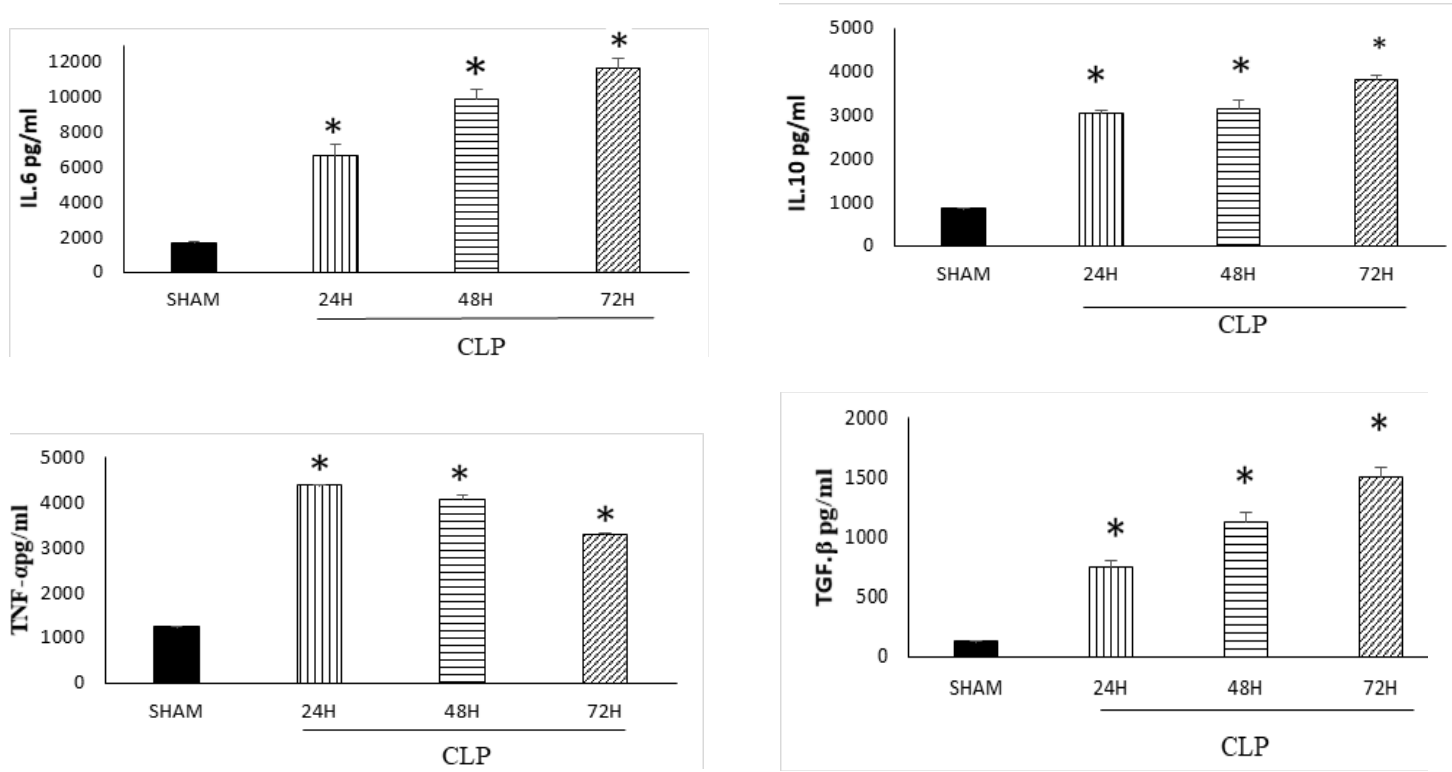

IminunoRegulation

Figure 4. Dynamic of cytokine production in the liver of CLP- induced sepsis mice

Both inflammatory and anti-inflammatory cytokines levels in the liver of septic mice shows a significant increase compared to the sham group. $\mathrm{P}<0.05$ defined as significant.

Increased level of serum IL-6 Increase of serum IL 6 level is one of the most important indicators of the acute phase of sepsis. Various studies have shown showed that this cytokine increases in the first 10 hours after induction of the model in the serum and decreases over time gradually [23, 24]. The mortality rate and severity of the liver response to infection depend on the amount of this cytokine. Studies have shown showed have shown that inhibiting IL-6 or its receptor can reduce its destructive effects [25]. In the CLP model created in the present study, the maximum level of IL-6 is was detected in the early 24 hours after CLP induction which gradually decreases decreased during the next days. However, the reverse trend was observed in the IL-6 production in the liver. The lowest amount of IL-6 was measured 24 hours after induction of the CLP model in the liver, which increased significantly $(\mathrm{P} \leq 0.05)$ over time. This result indicates that the function and dynamic of IL-6 in the serum do not represent the characteristics of this cytokine in the liver.

TNF- $\alpha$ is another inflammatory cytokine that that is was induced in sepsis and has had different effects depending on the stage and the severity of the disease [26]. Studies in the CLP sepsis model have shown showed have shown that neutralization of TNF- $\alpha$ in severe sepsis reduces the risk of systemic inflammatory response syndrome and mortality. In contrast, TNF- $\alpha$ neutralization in mild sepsis reduces TNF- $\alpha$ pro-coagulant effect and attenuates defense against microbial agents that lead to bacterial spread, organ destruction, and increased mor- tality as in the current study, we showed that the amount of TNF- $\alpha$ in the liver is higher than its amount in serum at the same time after induction of the model. In additionAlso, TNF- $\alpha$ levels decreases in the liver and increases in the serum during the study period.

IL-10 is an anti-inflammatory cytokine that is secretesd by immune cells and suppresses different immune responses, including antigen presentation, phagocytosis, and production of inflammatory cytokines production [27]. Based on evidence According to the evidence obtained from the CLP sepsis model, the production of IL-10 increases along with the production of inflammatory cytokines such as IL- 6 and TNF- $\alpha$ in serum, but the amount and timing of the production of this cytokine is important in determining its protective or destructive role in sepsis control $[28,29]$. Delay in IL-10 production or ineffective inadequate amounts of this cytokine it in the inflammatory phase of the sepsis in the CLP mouse model causes a sharp increase in the level of inflammatory cytokines and increases mortality [28].

While the high levels of serum IL-10 at the onset of the disease induces severe immunosuppression that increases the susceptibility to microbial infections and increases tissue damage and mortality [30, 31]. Based on According to the available evidence evidence documents, IL-10 production is stimulated in response to an increased in IL-6 and TNF- $\alpha$ cytokines and regulates their production [32]. The present study showsed that IL-10 cytokine level in- 
creases increased in both serum and liver during within 24 to 72 hours after induction of the CLP sepsis model, but an increase in IL-10 level, did do not necessarily lead to a decrease in IL- 6 and TNF- $\alpha$.

A closer look at the results in the liver and serum obtained in the liver and serum showsed that the inhibitory effect of IL-10 depends on the amount of inflammatory cytokine. An increase in IL-10 inhibits serum IL-6, which has reached about approximately $20,000 \mathrm{pg} / \mathrm{ml} \mathrm{mL}$ after 24 hours of induction, while it has had no inhibitory effect on IL-6 production in the liver, which has reached 12,000 $\mathrm{pg} / \mathrm{ml} \mathrm{mL}$ after 72 hours. In this regard, the increase in IL10 causes the inhibition of the TNF- $\alpha$ in the liver, which has reached about $4,000 \mathrm{pg} / \mathrm{ml} \mathrm{mL}$ after 24 hours of induction of the CLP model, while it has no suppressive effect on TNF- $\alpha$ production in serum, which reached $500 \mathrm{pg} / \mathrm{ml}$ $\mathrm{mL}$ after 72 hours. Transforming growth factor factor-beta (TGF- $\beta$ ) is a multifunctional cytokine that is secreted by many cells, including immune cells [33].

Different studies showed the pleiotropic immunomodulatory effects of TGF- $\beta$ in sepsis. Published evidences documents in about the CLP- induced sepsis model, demonstrated both the pro-inflammatory and anti-inflammatory role of this cytokine. Jong-Sup Bae and et.al et al. showed reported that an increase in the circulating level of TGF- $\beta$ enhances severe inflammatory responses and determines disease severity in the CLP sepsis model [34]. In a study conducted by Zang et al., the therapeutic effect of TGF- $\beta$ treatment was investigated on inflammatory responses in the liver and peripheral blood. The results showed that an increase in the level of serum TGF- $\beta$ enhanceds the production of NFkB and TNF- $\alpha$ in the liver and serum, respectively [35].

The results of the present study showed that the production of TGF- $\beta$ in the liver is higher than the peripheral blood. In additionBesides, during 72 hours after induction of the CLP sepsis model, TGF- $\beta$ production showed an increasing trend in the liver, and a decreasing trend in the serum. According to the present study, TGF- $\beta$ has an anti-inflammatory effect in on both the liver and peripheral blood, and an increase in its production is associated with a decrease in TNF- $\alpha$ levels.

Examination of inflammatory and anti-inflammatory cytokines in the liver and serum showsed that variation in the severity of inflammation in the organs and peripheral blood. varies. Inflammatory conditions of the serum do not necessarily reflect the inflammatory conditions of the affected organs in the CLP sepsis model. Therefore, in order to evaluate the CLP sepsis model and to determine the effectiveness of drugs, inflammatory responses in serum and contaminated organs should be considered, separately.

\section{Ethical Considerations}

\section{Compliance with ethical guidelines}

All ethical principles are considered in this article. The participants were informed about the purpose of the research and its implementation stages. This study was approved by the Iran Nnational Committee for Ethics in Biomedical Research (Code: IR.TMU.REC.1394.180).

Funding

This study was supported by the financial grants of Tarbiat Modares University and the National Animal Modeling Network and In vivo Research, Council for Development of Stem Cell Sciences and Technologies, Vice -Presidency for Science and Technology (Grant No.: 98/11641).

\section{Authors' contributions}

Conceptualization, writing - original draft: Sara Soudi, Arezou Khosrojerdi; Methodology, writing - review \& editing: Arezou Khosrojerdi; Funding acquisition, resources: Sara Soudi, Seyed Mahmoud Hashemi; Supervision: Sara Soudi, Ahmad Zavaran Hosseini, Seyed Mahmoud Hashemi.

\section{Conflicts of interest}

The authors declared no conflict of interest.

\section{References:}

[1] Gerdts V, Littel-van den Hurk SvD, Griebel PJ, Babiuk LA. Use of animal models in the development of human vaccines. Future Microbiology. 2007; 2(6):667-75. [DOI:10.2217/17460913.2.6.667] [PMID]

[2] Lipman NS, Perkins SE. Factors that may influence animal research: Laboratory animal medicine. American College of Laboratory Animal Medicine. 2002; 1143-84. [DOI:10.1016/B978-012263951-7/50032-6]

[3] Coers J, Starnbach MN, Howard JC. Modeling infectious disease in mice: Co-adaptation and the role of host-specific IFNY responses. PLoS Pathog. 2009; 5(5):e1000333. [DOI:10.1371/journal.ppat.1000333] [PMID] [PMCID]

[4] Sarkar S, Heise MT. Mouse models as resources for studying infectious diseases. Clinical Therapeutics. 2019; 41(10):1912-22. [DOI:10.1016/j.clinthera.2019.08.010] [PMID] [PMCID] 
[5] Swearengen JR. Choosing the right animal model for infectious disease research. Animal Models and Experimental Medicine. 2018; 1(2):100-8. [DOI:10.1002/ame2.12020] [PMID] [PMCID]

[6] Bailey M, Christoforidou Z, Lewis MC. The evolutionary basis for differences between the immune systems of man, mouse, pig and ruminants. Veterinary Immunology and Immunopathology. 2013; 152(1-2):13-9. [DOI:10.1016/j. vetimm.2012.09.022] [PMID]

[7] Mestas J, Hughes CC. Of mice and not men: Differences between mouse and human immunology. The Journal of Immunology. 2004; 172(5):2731-8. [DOI:10.4049/jimmut nol.172.5.2731] [PMID]

[8] Deutschman CS, Tracey KJ. Sepsis: Current dogma and new perspectives. Immunity. 2014; 40(4):463-75. [DOI:10.1016/j.immuni.2014.04.001] [PMID]

[9] Rudd KE, Johnson SC, Agesa KM, Shackelford KA, Tsoi D, Kievlan DR, et al. Global, regional, and national sepsis incidence and mortality, 1990-2017: Analysis for the Global Burden of Disease Study. The Lancet. 2020; 395(10219):20011. [DOI:10.1016/S0140-6736(19)32989-7]

[10] Fink MP. Animal models of sepsis. Virulence. 2014; 5(1):143-53. [DOI:10.4161/viru.26083] [PMID] [PMCID]

[11] Lewis AJ, Seymour CW, Rosengart MR. Current murine models of sepsis. Surgical Infections. 2016; 17(4):385-93. [DOI:10.1089/sur.2016.021] [PMID] [PMCID]

[12] Fink MP. Animal models of sepsis and its complications. Kidney International. 2008; 74(8):991-3. [DOI:10.1038/ ki.2008.442] [PMID]

[13] Deitch EA. Rodent models of intra-abdominal infection. Shock. 2005; 24(Suppl 1):19-23. [DOI:10.1097/01. shk.0000191386.18818.0a] [PMID]

[14] Poli-de-Figueiredo LF, Garrido AG, Nakagawa N, Sannomiya P. Experimental models of sepsis and their clinical relevance. Shock. 2008; 30(7):53-9. [DOI:10.1097/ SHK.0b013e318181a343] [PMID]

[15] Remick DG, Ward PA. Evaluation of endotoxin models for the study of sepsis. Shock. 2005; 24(Suppl 1):7-11. [DOI:10.1097/01.shk.0000191384.34066.85] [PMID]

[16] Chen P, Stanojcic M, Jeschke MG. Differences between murine and human sepsis. Surgical Clinics. 2014; 94(6):1135-49. [DOI:10.1016/j.suc.2014.08.001] [PMID]

[17] Dejager L, Pinheiro I, Dejonckheere E, Libert C. Cecal ligation and puncture: The gold standard model for polymicrobial sepsis? Trends in Microbiology. 2011; 19(4):198208. [DOI:10.1016/j.tim.2011.01.001] [PMID]

[18] Rittirsch D, Huber-Lang MS, Flierl MA, Ward PA. Immunodesign of experimental sepsis by cecal ligation and puncture. Nature Protocols. 2009; 4(1):31-6. [DOI:10.1038/ nprot.2008.214] [PMID] [PMCID]

[19] Nedeva C, Menassa JA, Puthalakath H. Sepsis: Inflammation is a necessary evil. Frontiers in Cell and Developmental Biology. 2019; 7:108. [DOI:10.3389/fcell.2019.00108] [PMID] [PMCID]

[20] Jason J, Archibald LK, Nwanyanwu OC, Byrd MG, Kazembe PN, Dobbie H, et al. Comparison of serum and cell- specific cytokines in humans. Clinical and Diagnostic Laboratory Immunology. 2001; 8(6):1097-103. [DOI:10.1128/ CDLI.8.6.1097-1103.2001] [PMID] [PMCID]

[21] Nesseler N, Launey Y, Aninat C, Morel F, Mallédant Y, Seguin P. Clinical review: The liver in sepsis. Critical Care. 2012; 16(5):1-8. [DOI:10.1186/cc11381] [PMID] [PMCID]

[22] Llorente C, Schnabl B. Fast-track clearance of bacteria from the liver. Cell Host \& Microbe. 2016; 20(1):1-2. [DOI:10.1016/j.chom.2016.06.012] [PMID]

[23] Weiss YG, Bellin L, Kim PK, Andrejko KM, Haaxma $\mathrm{CA}$, Raj N, et al. Compensatory hepatic regeneration after mild, but not fulminant, intraperitoneal sepsis in rats. American Journal of Physiology-Gastrointestinal and Liver Physiology. 2001; 280(5):G968-73. [DOI:10.1152/ ajpgi.2001.280.5.G968] [PMID]

[24] Li JL, Li G, Jing XZ, Li YF, Ye QY, Jia HH, et al. Assessment of clinical sepsis-associated biomarkers in a septic mouse model. Journal of International Medical Research. 2018; 46(6):2410-22. [DOI:10.1177/0300060518764717] [PMID] [PMCID]

[25] Riedemann NC, Neff TA, Guo RF, Bernacki KD, Laudes IJ, Sarma JV, et al. Protective effects of IL-6 blockade in sepsis are linked to reduced $\mathrm{C} 5 \mathrm{a}$ receptor expression. The Journal of Immunology. 2003; 170(1):503-7. [DOI:10.4049/ jimmunol.170.1.503] [PMID]

[26] Rice TW, Bernard GR. Therapeutic intervention and targets for sepsis. Annual Review of Medicine. 2005; 56:22548. [DOI:10.1146/annurev.med.56.082103.104356] [PMID]

[27] Schulte W, Bernhagen J, Bucala R. Cytokines in sepsis: Potent immunoregulators and potential therapeutic targets-an updated view. Mediators of Inflammation. 2013; 2013:165974. [DOI:10.1155/2013/165974] [PMID] [PMO CID]

[28] Kato T, Murata A, Ishida H, Toda H, Tanaka N, Hayashida $\mathrm{H}$, et al. Interleukin 10 reduces mortality from severe peritonitis in mice. Antimicrobial Agents and Chemotherapy. 1995; 39(6):1336-40. [DOI:10.1128/AAC.39.6.1336] [PMID] [PMCID]

[29] Latifi SQ, O'Riordan MA, Levine AD. Interleukin-10 controls the onset of irreversible septic shock. Infection and Immunity. 2002; 70(8):4441-6. [DOI:10.1128/IAI.70.8.44414446.2002] [PMID] [PMCID]

[30] Steinhauser ML, Hogaboam CM, Kunkel SL, Lukacs NW, Strieter RM, Standiford TJ. IL-10 is a major mediator of sepsis-induced impairment in lung antibacterial host defense. The Journal of Immunology. 1999; 162(1):392-9. [PMID]

[31] Chuang TY, Chang HT, Chung KP, Cheng HS, Liu CY, Liu YC, et al. High levels of serum macrophage migration inhibitory factor and interleukin 10 are associated with a rapidly fatal outcome in patients with severe sepsis. International Journal of Infectious Diseases. 2014; 20:13-7. [DOI:10.1016/j.ijid.2013.12.006] [PMID]

[32] Knolle P, Löser E, Protzer U, Duchmann R, Schmitt E, Zum Bü Schenfelde KH, et al. Regulation of endotoxin-induced IL-6 production in liver sinusoidal endothelial cells and Kupffer cells by IL-10. Clinical \& Experimental Immunology. 1997; 107(3):555-61. [DOI:10.1046/j.1365-2249.1997. d01-959.x] [PMID] [PMCID] 
[33] Massagué J. TGF $\beta$ signalling in context. Nature Reviews Molecular Cell Biology. 2012; 13(10):616-30. [DOI:10.1038/ nrm3434] [PMID] [PMCID]

[34] Bae JS, Lee W, Nam JO, Kim JE, Kim SW, Kim IS. Transforming growth factor $b$-induced protein promotes severe vascular inflammatory responses. American Journal of Respiratory and Critical Care Medicine. 2014; 189(7):77986. [DOI:10.1164/rccm.201311-2033OC] [PMID]

[35] Zhang Y, Xing J. Effect of transforming growth factor- $\beta 1$ on monocyte toll-like receptor 4 expression in septic rats. World Journal of Emergency Medicine. 2011;2(3):228-31. [DOI:10.5847/ wjem.j.1920-8642.2011.03.013] [PMID] [PMCID] 
This Page Intentionally Left Blank 